\title{
Pharmaceuticals in the Built and Natural Water Environment of the United States
}

\section{Randhir P. Deo ${ }^{1}$ and Rolf U. Halden ${ }^{2,3,4, *}$}

1 Chemistry Program, College of Arts and Sciences, Grand Canyon University, Phoenix, AZ 85017, USA; E-Mail: randhir.deo@gcu.edu

2 Center for Environmental Security, Biodesign Institute at Arizona State University, 781 E. Terrace Road, P.O. Box 875904, Tempe, AZ 85287-5904, USA

3 Security and Defense Systems Initiative, Arizona State University, Tempe, AZ 85287-5904, USA

4 Department of Environmental Health Sciences, Bloomberg School of Public Health, Johns Hopkins University, Baltimore, MD 21205, USA

* Author to whom correspondence should be addressed; E-Mail: halden@asu.edu; Tel.: +1-480-727-0893; Fax: +1-480-965-6603.

Received: 22 June 2013; in revised form: 8 August 2013 / Accepted: 28 August 2013 / Published: 11 September 2013

\begin{abstract}
The known occurrence of pharmaceuticals in the built and natural water environment, including in drinking water supplies, continues to raise concerns over inadvertent exposures and associated potential health risks in humans and aquatic organisms. At the same time, the number and concentrations of new and existing pharmaceuticals in the water environment are destined to increase further in the future as a result of increased consumption of pharmaceuticals by a growing and aging population and ongoing measures to decrease per-capita water consumption. This review examines the occurrence and movement of pharmaceuticals in the built and natural water environment, with special emphasis on contamination of the drinking water supply, and opportunities for sustainable pollution control. We surveyed peer-reviewed publications dealing with quantitative measurements of pharmaceuticals in U.S. drinking water, surface water, groundwater, raw and treated wastewater as well as municipal biosolids. Pharmaceuticals have been observed to reenter the built water environment contained in raw drinking water, and they remain detectable in finished drinking water at concentrations in the $n g / L$ to $\mu \mathrm{g} / \mathrm{L}$ range. The greatest promises for minimizing pharmaceutical contamination include source control (for example, inputs from intentional flushing of medications for safe disposal, and sewer overflows), and improving efficiency of treatment facilities.
\end{abstract}


Keywords: drinking water; sewage sludge; pharmaceuticals; review

\section{Introduction}

Intended uses of pharmaceuticals in humans and animals are plentiful and include the prevention, diagnosis, and therapy of diseases as well as cosmetic and lifestyle purposes [1]. In recent years, however, their occurrence in the environment has raised concerns, both nationally and internationally, regarding implied risks posed to aquatic and terrestrial life forms, including humans [2-7]. In the United States (U.S.), pharmaceuticals have been found to occur throughout the water environment [8-13], including the drinking water supply [14-18]. Whereas the perceived and actual risks of trace levels of pharmaceuticals in drinking water is a topic of ongoing discussion, this review concentrates on the sources and pathways of water contamination in the U.S. to assess our understanding of the occurrence of pharmaceuticals in U.S. drinking water, and to identify opportunities for pollution control.

Environmental exposures of humans and aquatic organisms to pharmaceuticals have been reported [19-25] and the associated risks evaluated [17,26-28]. For example, human health impacts were assessed from exposure to pharmaceutically active compounds in drinking water [14-18] and edible fish [19-25]. Additionally, specific modes of action of pharmaceuticals have been evaluated in humans and mammals [29], including an analysis of metabolism and excretion by humans [30]. Overall, these studies conclude that, based on current knowledge, the presence of trace levels of pharmaceuticals poses negligible or only minor risks to humans. Exposure of aquatic organisms also is well established [31] and extends into coastal waters, as illustrated by reports on the antibacterial chemical triclosan, that was measured in blood plasma of wild bottlenose dolphins (Tursiopstruncatus) (0.025-0.11 ng/g wet weight), and in estuarine surface water samples (4.9-14 ng/L) [20].

Concerning the built (man-made) water environment, a significant volume of literature explored the performance of treatment plants for the removal of pharmaceuticals from raw wastewater (sewage) [32-36] and from raw drinking water [37-39]. Additional studies investigated various strategies for efficient removal and transformation of pharmaceuticals using advanced treatment employing processes of chemical [32,40-43], biological [44-47] and physical nature [48,49]. Since not all pharmaceuticals present in sewage are the result of intentional intake, metabolism and excretion, some researchers have investigated the composition of wastewaters from the pharmaceutical industry [50], and healthcare facilities [51], as well as the importance of disposal of unwanted or leftover pharmaceuticals into sanitary sewers [1,2,52-56].

The aforementioned reviews and articles carry valuable information and discussion on occurrences, treatment efficiencies, and risk assessments of pharmaceuticals in the environment. However, our focus in this review is to specifically examine the occurrences of pharmaceutical compounds in U.S. drinking water, in the context of the role of the different point sources of the built water environment, the interconnectivity of the built and natural water environments, and to identify opportunities for effectively controlling environmental contamination with pharmaceuticals in a sustainable fashion. A perspective on this issue is essential, however, for properly managing risks associated with the occurrence of pharmaceutical compounds in the built and natural water environment. 
In this review, we first examine the interplay of the built water environment and the natural water environment to inform the management of pharmaceutical pollution; Second, we survey peer-reviewed publications for available data on the identity and concentration of pharmaceuticals present in various compartments of the water environment, exclusively in the U.S.; Third, we discuss the persistence and risk of pharmaceuticals in groundwater and drinking water. Fourth and finally, we propose strategies and criteria for minimizing occurrences of pharmaceuticals in drinking water, and in the preceding matrices of the natural and built water environment.

For the purpose of this review, we defined "pharmaceuticals" as prescription and non-prescription drugs that are either ingested or topically applied for prevention and/or cure of diseases and injuries. Thus, we included antimicrobial compounds that are used heavily in clinics and hospitals; however, we excluded other substances such as naturally occurring hormones, flavors and fragrances, cosmetics, and personal care products. The literature search was conducted using the Web of Science database, using the keyword "pharmaceutical(s)" in various aforementioned matrices of the built and natural water environments, including sewage sludge. Only maximum concentrations of the measured individual pharmaceuticals were included in this study. Also, we restricted our search to all the studies done exclusively in the U.S.

\section{Built and Natural Water Environment}

\subsection{General Overview}

The built water environment is a complex network of infrastructure comprising manmade lakes and reservoirs, canals, the sewerage and water distribution systems, drinking water treatment plants (DWTPs) and wastewater treatment plants (WWTPs), as well as rivers and aquifers reliant on WWTP effluent as the principal recharge mechanism. Significant additions to the built water environment resulted from the Clean Water Act, which was implemented in 1972 with the objective to "restore and maintain the chemical, physical, and biological integrity of the Nation's waters" [57]. One of the provisions of this regulation was to prohibit discharge of toxic pollutants from point sources, including domestic households and industrial facilities. The legislation also laid the foundation for the current practice of combining industrial and domestic wastewaters before treatment at the WWTP. In this context, it is important to note that pretreatment of high-strength industrial waters is widely practiced in the U.S. prior to their release into municipal sewer systems.

Despite these efforts, pharmaceuticals are known to occur in U.S. water resources, which behooves us to more closely study and better manage the fate and migration of pharmaceuticals through the water environment. Figure 1 shows a number of major components of the built water environment and the natural water environment. It identifies important compartments of the built water environment, such as sewage systems, WWTPs, DWTPs and the water distribution system, and shows how this manmade infrastructure is in communication with multiple components of the natural water environment, including surface water (rivers, lakes, oceans, as well as aquifers) and groundwater. Due to this connectivity, pharmaceuticals frequently straddle the interface of the built and natural water environments, thereby posing potential risks to humans as well as to aquatic and other terrestrial life forms that rely on water resources to survive and flourish. 
Figure 1. Schematic showing inputs of pharmaceuticals to, and the interconnectivity of, the natural and built water environment.

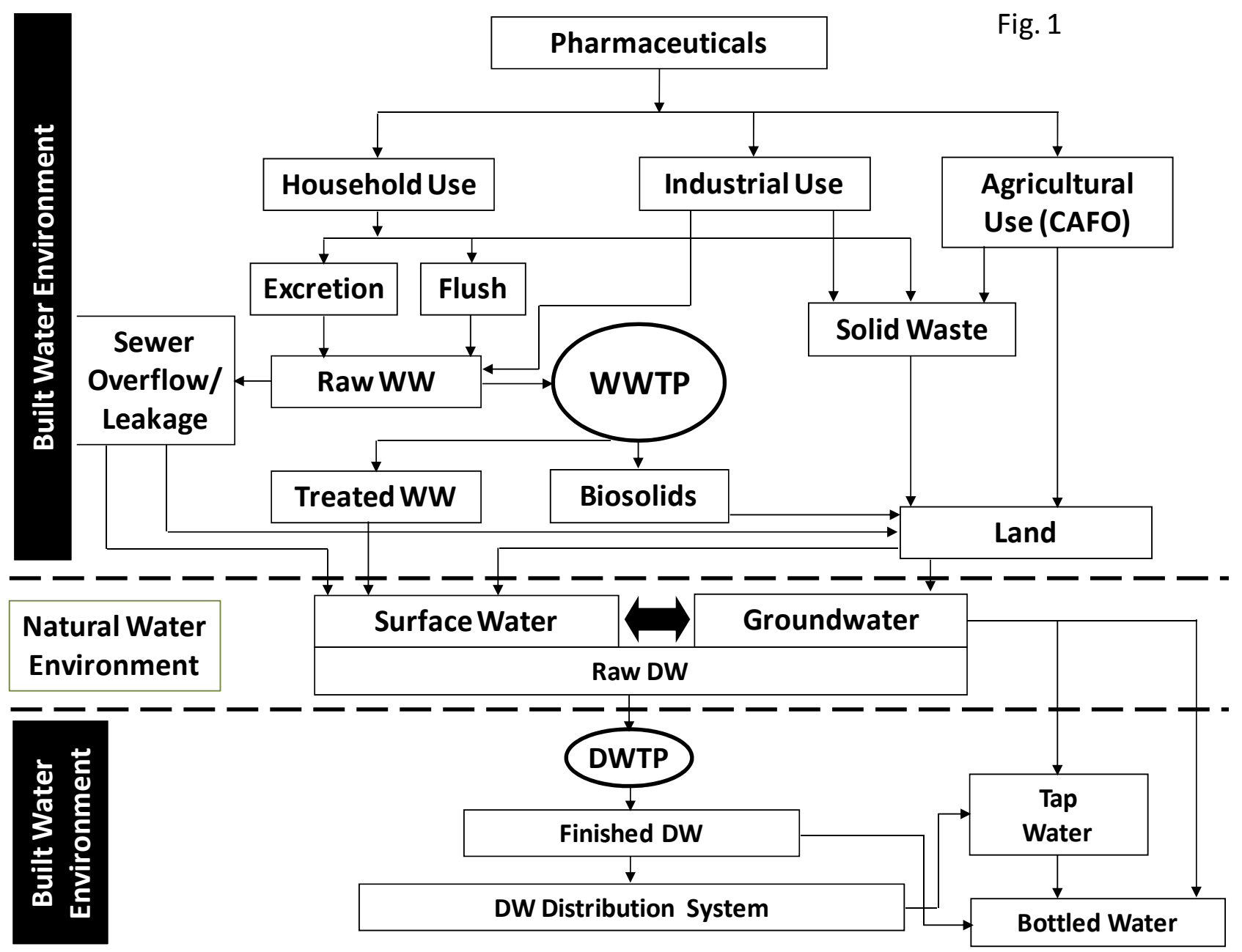

The major routes of pharmaceutical administration include enteral (e.g., oral), parenteral (e.g., injection), topical (e.g., skin surface), and inhalation. The ingested pharmaceuticals (mainly via enteral and parenteral administration) are excreted as un-metabolized or metabolized products, whereas the topically applied substances that do not enter the body by absorption also can be washed down the drain $[33,52]$. These pharmaceuticals are combined in the sewer system with black water (feces and urine) and gray water (domestic process waters from, e.g., washing, bathing, showering and kitchen use) to form raw wastewater or its synonym, sewage (Raw WW or RWW). Expired and unwanted (leftover) pharmaceuticals may be flushed down the drain, thereby leading to direct loading to wastewater [53]. Another source of pharmaceutical contamination in Raw WW is from the influx of waste from pharmaceutical manufacturing companies [50] and healthcare facilities [51].

Raw WW is conveyed to WWTPs whose primary goal is the removal of pathogens, turbidity, odor, color, Biological Oxygen Demand (BOD) and nutrients (primarily nitrogen and phosphorus) through a combination of physical, biological and chemical treatment [2]. However, their ability to also remove to a significant degree, the Pharmaceuticals and Personal Care Products (PPCPs), and other commodity chemicals is widely recognized and has been reviewed both from a mechanistic and quantitative perspective [58]. There are two process streams exiting the WWTPs: aqueous flow in the form of 
treated wastewater (Treated WW or TWW); and the municipal wastewater residuals or sewage sludge, which is an unwanted byproduct and that can be converted to so-called biosolids via additional treatment processes, including aerobic and/or anaerobic digestion, lime stabilization, and dewatering [59]. Treated WW is either reclaimed for land irrigation and farming or discharged into surface waters (streams, lakes, rivers, ponds, etc.) to close the water cycle. In coastal settings, biological sewage treatment is often omitted, and the effluent of primary treatment is directly discharged into the ocean. Pharmaceuticals discharged into surface waters may cause contamination of groundwater in aquifers, wells, springs and sumps either via direct leaching into the river bed or following application on land in irrigation water [8,11].

Pharmaceuticals may also enter surface water and groundwater through leaching of land-based pharmaceutical waste and solid waste contaminated with drugs. Major sources are unwanted or leftover drugs in domestic solid waste from residential households [52], from the pharmaceutical industry [50,60,61], from farm operations that land apply drug-tainted biosolids [62,63], and from animal waste that may contain excreted pharmaceuticals and partially metabolized drugs $[40,64]$.

Another possible pathway for surface water and groundwater contamination is from leaking sewage distribution lines or overflows of combined sewer systems and, less prominent, overflows of sanitary sewer systems, both occurring under conditions of heavy rainfall or snowmelt. Although these overflows are seasonal/occasional, their impact of contamination can be significant, since the discharged sewer may contain untreated pharmaceuticals that are washed directly into surface water from where it may infiltrate into groundwater [65-67].

In the U.S., as in many other countries, groundwater can and is being used directly for consumption as drinking water without any treatment, particularly in rural and remote settings [68]. In contrast, surface water typically is subject to a multi-barrier treatment train to remove chemical and biological contaminants. Ocean water also may serve as a source of drinking water but it undergoes extreme treatment in the form of either distillation or reverse osmosis filtration. Raw drinking water (Raw DW or RDW) is processed in DWTPs to produce finished drinking water (Finished DW or FDW) that is ready for distribution as tap water or bottling, distribution and retail (Figure 1).

\subsection{Occurrence and Distribution of Pharmaceuticals in the Built and Natural Water Environment}

In the following section, we present the number of pharmaceuticals distributed according to their highest concentration reported in each of the concentration ranges in various compartments of the built and natural water environments (Figure 2). The highest concentration values and names of the individual pharmaceuticals occurring in Raw WW, Treated WW, Surface Water, Groundwater, Raw DW, and Finished DW are provided Tables S1 to S6, respectively, in the Supplementary Information (SI). For simplicity and to avoid redundancy, each individual pharmaceutical measured in each water matrix is represented in Figure 2 only once and only in the histogram representing the highest concentration range. No pharmaceutical is represented in more than one concentration range within each water matrix with the implicit understanding that its presence at sub-maximal concentrations constitutes the rule rather than the exception.

The numbers of pharmaceuticals detected in each of the down gradient matrices include 73 in RWW, 92 in TWW, 91 in SW, 33 in GW, 37 in RDW, and 23 in FDW. It is important not to draw 
potentially misleading conclusions from the data presented in Figure 2 regarding the treatment efficiency of infrastructure and the attenuation of drugs in the environment. This could be misleading because the maximum concentrations of pharmaceuticals included in this study are from different discrete geographical locations within U.S., and the measurement objective was not necessarily to investigate the same set of pharmaceuticals in the different water matrices. Nevertheless, occurrence of lesser number and lower concentration range of pharmaceuticals in drinking water is noted from a human health perspective, regardless of identity or geographical location.

Figure 2. Number of pharmaceuticals detected in various water matrices of the built water environment. Each pharmaceutical is represented only once and shown in the category reflecting its respective maximum concentration reported in a given aquatic compartment.
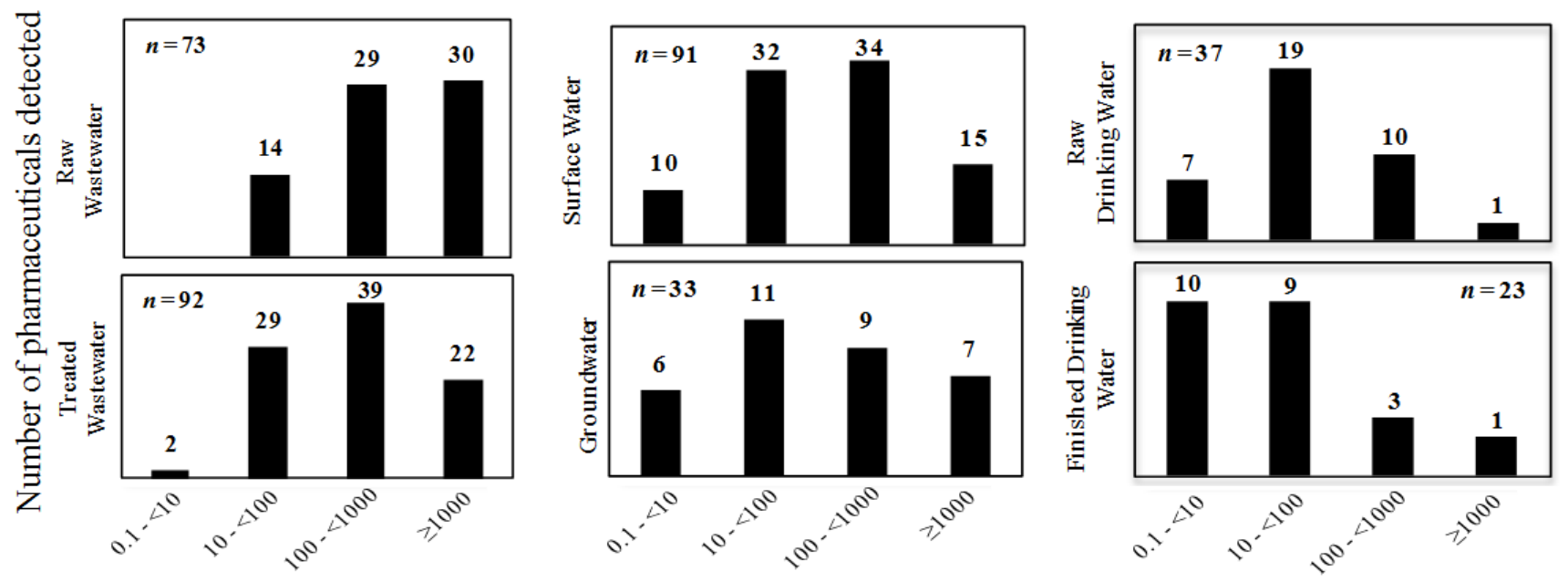

Concentration range $(\mathrm{ng} / \mathrm{L})$

The apparent increase in the total number of pharmaceuticals from RWW (total of 73) to TWW (total of 92) is counter-intuitive. Only 62 pharmaceuticals detected were common between these two matrices, which may reflect that different sets of pharmaceuticals were measured in the individual studies examined here. Other potential explanations for this observation include (i) deconjugation of metabolites and release of the parent compounds during treatment; (ii) analytical difficulties that lead to higher detection limits in RWW when compared to TWW; (iii) a less comprehensive monitoring of RWW compared with TWW; and (iv) the common practice in the analytical laboratory of filtering RWW but not necessarily TWW prior to analysis. Since RWW represents a mixture of inputs from domestic, municipal and industrial sources entering the WWTP, it is possible that higher than reported concentrations of pharmaceuticals may be present in specific process waters prior to mixing and entry into WWTPs. Wastewaters discharged by the pharmaceutical industry could constitute a particularly strong source term, as revealed in a report by the United States Geological Survey (USGS) [50].

Use of filtration during standard sample processing can remove a significant fraction of the hydrophobic organic compound mass contained in the sample of interest. A recent study reported that up to $86 \%$ of the mass of tonalide can be sorbed to filterable material and thus be excluded from chemical analyses, due to the common practice of filtering aqueous samples in general and raw sewage in particular [69]. Thus, any differences from study to study in both the occurrence and concentration 
of drugs in a given water matrix may be real or only apparent. Biased data can result from both sample processing and analyte detection strategies utilized [69].

Thirty-three different pharmaceuticals have been reported in U.S. GW and are provided here in units of $\mathrm{ng} / \mathrm{L}$ for maximum concentrations reported: acetaminophen (1890), caffeine (290), carbamazepine (420), ciprofloxacin (45), codeine (214), dehydronifedipine (22), diclofenac (46), dilantin (22), diltiazem (28), 1,7-dimethylxanthine (57), erythromycin (2380), 17- $\alpha$-ethinylestradiol (230), fluoxetine (56), gemfibrozil (6860), ibuprofen (3110), lincomycin (1900), meprobamate (8.6), naproxen (0.7), oestriol (6.4), oestrone (1), oxybenzone (7.5), oxytetracycline (130), pentoxifylline (34), primidone (2.8), sulfadimethoxine (130), sulfamerazine (54), sulfamethazine (3600), sulfamethazole (170), sulfamethoxazole (1110), sulfathiazole (305), tetracycline (500), triclosan (53), and trimethoprim (18) (Figure 2, Table 1).

In order for a compound to become detectable in groundwater, it either must have passed through the wastewater treatment processes prior to injection into the subsurface for aquifer recharge or it must have resisted microbial transformation, and sorption to soils and sediments during the slow soil infiltration process following application of drug-laden biosolids [11]. Alternatively, compounds may enter shallow and deeper groundwater from urination, defecation, sewer overflows, leaking sewage distribution lines, and/or through leaching of pharmaceuticals contained in waste resulting from agriculture use, such as Concentrated Animal Feeding Operation (CAFO), as indicated in Figure 1.

Furthermore, twenty-three different pharmaceuticals have been reported in U.S. FDW. Their maximum concentrations are provided in units of $\mathrm{ng} / \mathrm{L}$ in parentheses: acetaminophen (28), atenolol (26), caffeine (180.8), carbamazepine (258), codeine (30), cotinine (25), dehydronifedipine (4), diazepam (0.33), dilantin (32), erythromycin (1.3), fluoxetine (0.82), gemfibrozil (6.5), genistein (2.9), ibuprofen (1350), iopromide (31), lincomycin (4.4), meprobamate (43), naproxen (8), primidone (1.3), sulfamethoxazole (20), sulfathiazole (10), triclosan (734), and trimethoprim (1.7) (Figure 2, Table 1)).

The presence of pharmaceuticals in FDW may be related to multiple factors, including the pharmaceuticals' physical-chemical properties that allowed them to resist general biological, physical and chemical transformation processes, specific efficiency and/or overload of the treatment facilities (WWTP and DWTP) they passed through, and their respective initial mass loadings [66,70,71].

Whether long-term risks exist from chronic exposure to these compounds at low levels is a more difficult question to answer. Long-term, low-level exposures may involve toxicological mechanisms different from those observed in short-term, high-dose studies [71]. Furthermore, future demand for drinking water is expected to increase due to population growth and shortening of the water loop. Increased reliance on aggressive water reuse already is a key driver of research on contaminants of emerging concern (CECs). This notion is supported by the occurrence of pharmaceuticals in TWW ( $n=92$ drugs), SW ( $n=91$ drugs), GW ( $n=33$ drugs), and RDW ( $n=37$ drugs). Although generalizations are difficult to formulate, most immediate potential human health risks likely stem from elevated levels of pharmaceuticals in FDW, followed by drinking of untreated groundwater, which is more common in rural populations. 
Table 1. Maximum concentrations of pharmaceuticals detected in Groundwater (GW) and in Finished Drinking Water (FDW) of the United States. Also shown are the Predicted No-Effect Concentration (PNEC) and the calculated Risk Quotient (RQ).

\begin{tabular}{|c|c|c|c|c|c|}
\hline Pharmaceuticals & PNEC (ng/L) & GW (ng/L) & RQ (GW) & FDW (ng/L) & RQ (FDW) \\
\hline Acetaminophen & $1,000[72]$ & $1,890[68]$ & 1.890 & $28[86]$ & 0.028 \\
\hline Atenolol & $3.1 \times 10^{5}[73]$ & NA & - & $26[37]$ & 0.01 \\
\hline Caffeine & $1.0 \times 10^{7}[64]$ & $290[68]$ & 0.01 & $180.8[86]$ & 0.01 \\
\hline Carbamazepine & $420[74]$ & $420[68,79]$ & 1.00 & $258[87]$ & 0.614 \\
\hline Ciprofloxacin & $5[75]$ & $45[8]$ & 9.0 & NA & - \\
\hline Codeine & $2,900^{\mathrm{a}}$ & $214[68]$ & 0.07 & $30[88]$ & 0.01 \\
\hline Cotinine & $5,200^{a}$ & NA & - & 25 [87] & 0.01 \\
\hline Dehydronifedipine & $15,000^{\mathrm{a}}$ & $22[80]$ & $<0.01$ & $4[87]$ & 0.01 \\
\hline Diazepam & $4,300[76]$ & NA & - & $0.33[14]$ & 0.01 \\
\hline Diclofenac & $460[77]$ & $46[79]$ & 0.1 & NA & - \\
\hline Dilantin (Phenytoin) & $1,800^{\mathrm{a}}$ & $22[79]$ & - & $32[37]$ & 0.018 \\
\hline Diltiazem & $920^{\mathrm{a}}$ & $28[80]$ & 0.03 & NA & - \\
\hline 1,7-dimethylxanthine & $8,000^{\text {a }}$ & $57[80]$ & 0.007 & NA & - \\
\hline Erythromycin & 20 [77] & $2,380[81]$ & 119 & $1.3[89]$ & 0.065 \\
\hline 17- $\alpha$-ethinylestradiol & $1,800^{\mathrm{a}}$ & $230[8]$ & 0.128 & NA & - \\
\hline Fluoxetine & 47 [77] & $56[80]$ & 1.191 & $0.82[14]$ & 0.017 \\
\hline Gemfibrozil & 780 [77] & $6,860[82]$ & - & $6.5[90]$ & 0.008 \\
\hline Genistein & $550^{\mathrm{a}}$ & NA & - & $2.9[37]$ & 0.005 \\
\hline Ibuprofen & $1,000[72]$ & $3,110[80]$ & 3.11 & 1350 [91] & 1.350 \\
\hline Iopromide & $460,000^{a}$ & NA & - & 31 [89] & 0.01 \\
\hline Lincomycin & $13,000^{\mathrm{a}}$ & $1,900[83]$ & 0.025 & $4.4[86]$ & 0.01 \\
\hline Meprobamate & $110,000^{\mathrm{a}}$ & 8.6 [79] & - & $43[37]$ & 0.01 \\
\hline Naproxen & $640[77]$ & 0.7 [79] & - & 8 [89] & 0.013 \\
\hline Oestriol & $14,000^{\mathrm{a}}$ & 6.4 [79] & $<0.01$ & NA & - \\
\hline Oestrone & $4,800^{\mathrm{a}}$ & $1[79]$ & $<0.01$ & NA & - \\
\hline Oxybenzone & $3,500^{a}$ & 7.5 [79] & $<0.01$ & NA & - \\
\hline Oxytetracycline & $200[76]$ & 139 [84] & 0.695 & NA & - \\
\hline Pentoxifylline & $4,600^{\mathrm{a}}$ & 34 [79] & $<0.01$ & NA & - \\
\hline Primidone & $4,300^{a}$ & $2.8[85]$ & - & $1.3[92]$ & 0.01 \\
\hline Sulfadimethoxine & $248,000^{\mathrm{a}}$ & 130 [83] & $<0.01$ & NA & - \\
\hline Sulfamerazine & $116,000^{\mathrm{a}}$ & $54[81]$ & $<0.01$ & NA & - \\
\hline Sulfamethazine & $1.2 \times 10^{6 \mathrm{a}}$ & $3,600[83]$ & 0.001 & NA & - \\
\hline Sulfamethoxazole & $27[78]$ & $1,110[80]$ & 41.11 & 20 [89] & 0.741 \\
\hline Sulfathiazole & $5,000^{\mathrm{a}}$ & $305[81]$ & 0.061 & $10[88]$ & 0.002 \\
\hline Tetracycline & $90[76]$ & $500[7]$ & 5.6 & NA & - \\
\hline Triclosan & $1,550[72]$ & $53[8]$ & 0.034 & 734 [91] & 0.474 \\
\hline Trimethoprim & $1,000[64]$ & $18[68]$ & 0.018 & $1.7[86]$ & 0.002 \\
\hline
\end{tabular}

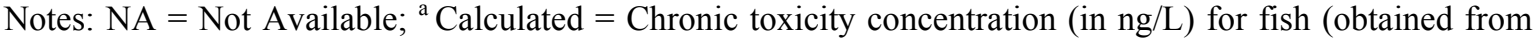
PBT Profiler [93])/100.

A comparison of the concentrations of pharmaceuticals occurring in GW and FDW against threshold concentrations of pharmaceuticals in drinking water is warranted when evaluating the 
magnitude of risks posed. Since quality standards are not yet available for pharmaceuticals in drinking water, we compared the highest concentrations of pharmaceuticals in GW and FDW against the predicted no-effect concentration (PNEC) value that is estimated from standard toxicity assays $[72,76,94,95]$. The result of this comparison is a calculated risk quotient (RQ), which is the ratio of the highest concentration of pharmaceuticals divided by the PNEC. We either used the lowest PNEC values available in the peer-reviewed literature, or estimated it by dividing the chronic (long-term) toxicity value for fish (obtained from PBT Profiler [93]) with an assessment factor of 100 [95] for extrapolating the test organism's chronic toxicity to the corresponding anticipated human no-effect concentration $[72,94,96]$.

Table 1 shows PNEC and RQ values available for all the pharmaceuticals in GW and FDW. In GW, acetaminophen, carbamazepine, erythromycin, fluoxetine, ibuprofen, sulfamethoxazole, and tetracycline have RQ value $>1$, and thus may pose a potential risk to humans, if the respective water is consumed without any (point-of-use) treatment. On the other hand, FDW has only ibuprofen with RQ value $>1$.

\subsection{Pharmaceuticals in Municipal Sludge}

An unwanted byproduct of wastewater treatment is sewage sludge that typically is treated to achieve stabilization and enable its application on land as biosolids according to federal and state guidelines. Municipal sludge used as fertilizer or soil conditioner is the subject of recent investigations as a source of organic pollutants in soils and adjacent aquatic environments [58,97,98]. The high organic carbon content of sewage sludge favors preferential sorption and enrichment of hydrophobic organic compounds during wastewater treatment process $[58,99,100]$.

Figure 3 shows the number of pharmaceuticals distributed according to their maximum concentration (in units of $\mu \mathrm{g} / \mathrm{kg}$ dry weight) reported in each of the concentration ranges in sewage sludge (Panel A), and the identity and maximum concentrations of pharmaceuticals occurring in $>10,000 \mu \mathrm{g} / \mathrm{kg}$ dry weight concentration range (Panel B). The most abundant compounds are the two antimicrobial compounds, triclocarban $(441,000)$ and triclosan $(133,000)$. Other major contributors are the antibiotics ciprofloxacin (47,500), ofloxacin $(58,100)$, and sulfanilamide $(15,600)$. The antihistamine diphenhydramine $(22,000)$ and the pain-reliever ibuprofen $(11,900)$ contribute a lesser but still substantial mass fraction. Pharmaceuticals reported in biosolids at maximum concentrations of 1000 to $<10,000 \mu \mathrm{g} / \mathrm{kg}$ include acetaminophen, anhydrotetracycline, azithromycin, caffeine, carbamazepine, chlortetracycline, cimetidine, clindamycin, 1,7-dimethylxanthine, doxycycline, 4-epianhydrotetracycline, 4-epitetracycline, fluoxetine, gemfibrozil, isochlortetracycline, metformin, miconazole, minocycline, naproxen, norfloxacin, ranitidine, sarafloxacin, and tetracycline. Maximum concentrations between 100 and $<1000 \mu \mathrm{g} / \mathrm{kg}$ were reported for anhydrochlortetracycline, clofibric acid, codeine, cotinine, demeclocycline, diclofenac, diltiazem, 4-epichlortetracycline, erythromycin (total), erythromycin- $\mathrm{H}_{2} \mathrm{O}, 17$ alpha-ethinylestradiol, norfluoxetine, estriol, estrone, oxytetracycline, paroxetine, salicylic acid, sulfadiazine, sulfamerazine, sulfamethoxazole, thiabendazole, trimethoprim, and virginiamycin. Maximum levels in biosolids of 10 to $<100 \mu \mathrm{g} / \mathrm{kg}$ were found for aspirin, albuterol, clarithromycin, dehydronifedipine, enrofloxacin, 4-epioxytetracycline, ketoprofen, lincomycin, lomefloxacin, oxolinic acid, roxithromycin, sulfachloropyridazine, sulfadimethoxine, sulfamethazine, sulfathiazole, and sulfisoxazole. At maximum concentrations of 0.1 to $<10 \mu \mathrm{g} / \mathrm{kg}$, only one drug, 
ormetoprim, was reported to occur in biosolids. The maximum concentration values and names of the individual pharmaceuticals occurring in Sewage Sludge are provided Table S7 in the Supplementary Information (SI).

Figure 3. (A) Number of pharmaceuticals detected in sewage sludge. Only maximum concentrations of the pharmaceuticals were included and categorized into different concentration ranges; (B) Identity and maximum concentrations of pharmaceuticals detected in sewage sludge at concentrations exceeding $10,000 \mu \mathrm{g} / \mathrm{kg}$ dry weight.
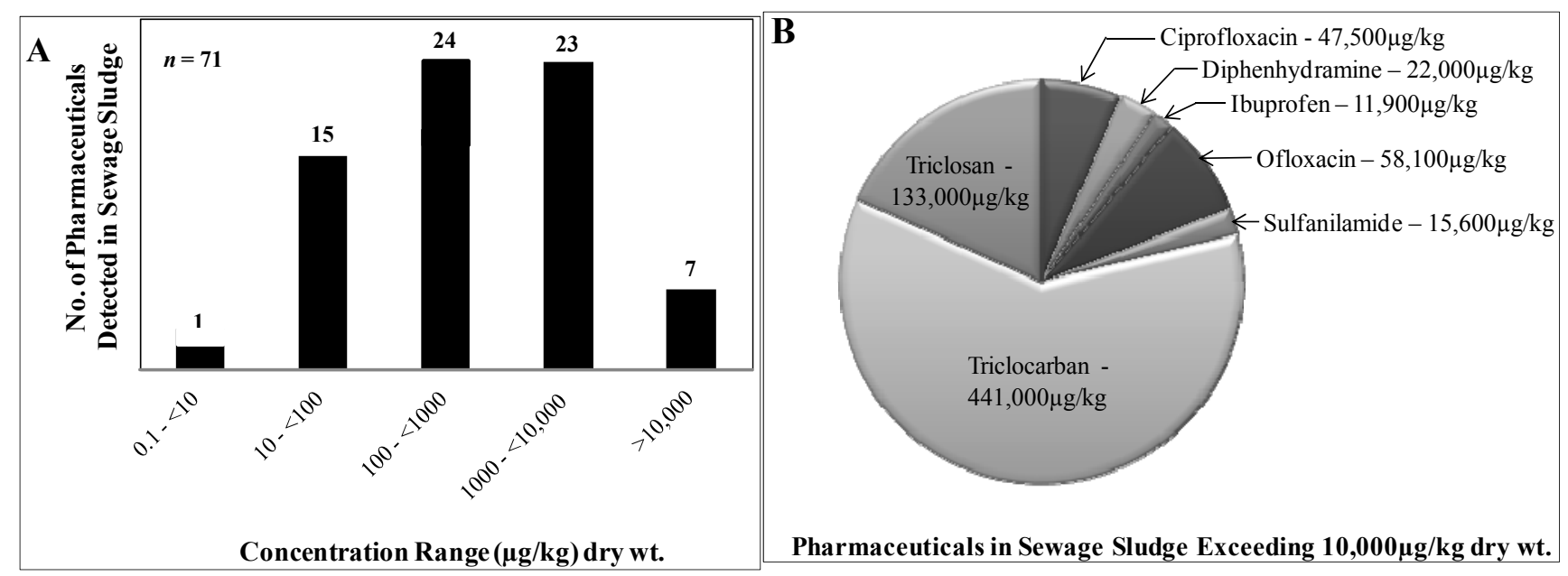

The accumulation of certain pharmaceuticals by sorption to sewage sludge can aid in the removal from the water environment but also can cause problems later on during disposal of these materials [8,97]. Today, approximately $50 \%$ of U.S. sewage sludge is applied on land as biosolids for inexpensive disposal and as a fertilizer or soil conditioner [101]. The application of biosolids laced with pharmaceuticals can pose secondary risks to water resources via leaching into groundwater and contamination of surface waters from runoff [63,102-105].

Additionally, pharmaceuticals contained in land-applied biosolids can directly pose risk to the environment and humans. Depending on their physical-chemical properties, pharmaceuticals can be strongly sorbed to soil and persist for a long time, or cause toxicity to soil bacteria and other microorganisms, thereby adversely impacting soil quality [59]. Furthermore, pharmaceuticals can be bioaccumulated into plants and crops that form part of the human diet. For example, bioaccumulation has been reported for sulfamethazine on lettuce, potato and corn [106], for chlortetracycline on corn, green onions and cabbage [107], and for carbamazepine, sulfamethoxazole, salbutamol, trimethoprim on Chinese cabbage (Brassica campestris) [108].

\section{Sustainable Management of Pharmaceuticals}

Reports of pharmaceuticals in the environment are projected to increase in the future due to increased monitoring efforts, a shortening of the water cycle, increased drug consumption, and the availability of advanced measurement technologies for trace analysis of pharmaceuticals in complex matrices. These projections demand sustainable management of pharmaceuticals in our water environment.

For example, progress has been made toward the use of advanced processing techniques that may minimize the occurrence of pharmaceuticals in drinking water. These advanced treatment techniques 
employ chemical [37], biological [36], and physical processes [34]. Chemical processes using advanced oxidation [109,110] and ozonation [39] have been shown to improve removal efficiency when used individually or in sequence [37,38,111,112]. For example, triclosan, ibuprofen, sulfamethoxazole, trimethoprim, naproxen, carbamazepine, phenytoin, diazepam, caffeine and fluoxetine removal efficiencies were improved by $>70 \%$ through ozonation at a dose of $2.5 \mathrm{mg} / \mathrm{L}$ [37]. Additionally, progress has been made towards developing "green" chemistry approaches, for example, using Fe-TAML catalysts for purifying environmental waters [113].

The improved removal efficiency mentioned above, however, needs to be further investigated in order to assess whether the treatment technique will result in complete degradation of the pharmaceutical compounds (the safe and desired end result of any treatment process), or whether it transformed the pharmaceuticals into other products that may or may not be safe, when occurring both in isolation or in a mixture.

Besides improving the efficiency of DWTP, controlling important point sources of pharmaceuticals ought to be a priority in minimizing water and soil contamination. Source control of pharmaceutical contamination begins with proper disposal of pharmaceutical waste streams, as well as expired and leftover pharmaceuticals. Daughton and colleagues have thoroughly reviewed the reasons for accumulation of pharmaceuticals and repercussions of disposing leftover pharmaceuticals into sewage and solid waste $[1,15,52,53,114]$. The recommendation from these reviews is simple: do not throw unused or leftover pharmaceuticals in the toilet or flush them down the drain. Proper disposal methods should be practiced, for example, dropping off pharmaceuticals at local facilities that collect them.

Environmental occurrence of pharmaceuticals is not really a new problem but one that had been concealed for decades due to the lack of both suitable analytical techniques and financial resources to enable monitoring using available methods. Detection methods have improved substantially in the past decade and will have to be revised continuously in the future to include new pharmaceuticals entering the market. Additionally, pharmaceuticals should be routinely monitored in environmental compartments and process flows that are in communication with drinking water resources (Figure 1) for early detection of potential hazards.

In addition to continued efforts to improve the removal efficiencies of WWTPs and DWTPs, pharmaceutical industries and academic research institutions may harness new technologies to design "green pharmaceuticals" [115]. Next generation "green pharmaceuticals" ideally will be designed to undergo removal and destruction in sewage and drinking water treatment works, while maintaining the therapeutic qualities of their contemporary counterparts in vivo in the target organism (i.e., humans and animals).

Furthermore, municipalities and academic institutions may engage in public education for proper use and disposal of pharmaceuticals in partnership with government agencies. Regulating agencies may take a more active role in implementing policies to curtail excessive application of pharmaceuticals in agribusiness, require risk assessment of new pharmaceuticals before market launch, and promote education on managing chemicals in a sustainable manner. 


\section{Summary and Conclusions}

Pharmaceuticals are subject to repeated transfer between the built water environment and the natural water environment. Typical cycles for polluting drugs include excretion or disposal into wastewater, incomplete removal during sewage treatment and entry of attenuated drug quantities into natural surface waters and terrestrial environments via treated WW and land application of biosolids. Reentry of drugs from the natural environment into the built water environment occurs during uptake of source water for the water supply. Removal of drugs during DW treatment is incomplete, causing the occurrence of $\mathrm{ng} / \mathrm{L}$ to $\mu \mathrm{g} / \mathrm{L}$ concentrations of certain pharmaceuticals in finished DW. Population growth and a shortening of the natural water cycle likely will lead to an increase in trace levels of drugs in DW unless pharmaceutical pollution will be managed more proactively in the future.

Risk reduction opportunities and continuing research needs exist in the areas of:

- Long-term effects of low-level pharmaceutical contamination on human health;

- Short- and long-term effects of pharmaceutical contamination on non-target organisms;

- Comprehensive evaluations of treatment works (DWTPs and WWTPs) to identify infrastructure that improves the removal efficiencies of pharmaceuticals, and minimizes associated costs;

- Enhanced monitoring of pharmaceuticals in the built water environment to facilitate accurate evaluation of removal efficiencies of treatment works and to identify all possible avenues by which pharmaceuticals enter the natural water environment (including sewer overflows, leachates from solid waste, and biosolids runoff);

- More targeted monitoring of pharmaceuticals that are toxic to indicator organisms, are produced in high-volume, and possess persistent physico-chemical properties (i.e., long environmental half-life);

- Design of pharmaceuticals that are susceptible to transformation (or degradation) by treatment works and/or natural processes (e.g., photolysis);

- Identification and elimination of high-strength wastewaters from the pharmaceutical industry;

- Partnerships between academic institutions, pharmaceutical industries, and government to promote public education for proper use and disposal of pharmaceuticals.

Given the importance of preserving the quality of natural waters and the security of the drinking water supply, it may be desirable to provide additional funding mechanisms to support these ongoing and suggested activities (e.g., through leveling of a modest tax on pharmaceutical sales).

\section{Acknowledgments}

This study was supported in part by the National Institute of Environmental Health Sciences (NIEHS) through research grants 1R01ES015445 and 1R01ES020889, and by the Johns Hopkins University Center for a Livable Future. The content is solely the responsibility of the authors and does not necessarily represent the official views of the NIEHS or the National Institutes of Health (NIH).

\section{Conflicts of Interest}

The authors declare no conflict of interest. 


\section{References}

1. Ruhoy, I.S.; Daughton, C.G. Beyond the medicine cabinet: An analysis of where and why medications accumulate. Environ. Int. 2008, 34, 1157-1169.

2. Daughton, C.G.; Ternes, T.A. Pharmaceuticals and personal care products in the environment: Agents of subtle change? Environ. Health Perspect. 1999, 107, 907-938.

3. Dong, Z.; Senn, D.B.; Moran, R.E.; Shine, J.P. Prioritizing environmental risk of prescription pharmaceuticals. Regul. Toxicol. Pharmacol. 2013, 65, 60-67.

4. Kummerer, K. The presence of pharmaceuticals in the environment due to human use-Present knowledge and future challenges. J. Environ. Manag. 2009, 90, 2354-2366.

5. Kummerer, K. Pharmaceuticals in the Environment. In Annual Review of Environment and Resources; Gadgil, A., Liverman, D.M., Eds.; Annual Reviews: Palo Alto, CA, USA, 2010; pp. 57-75.

6. Boxall, A.B.A.; Rudd, M.A.; Brooks, B.W.; Caldwell, D.J.; Choi, K.; Hickmann, S.; Innes, E.; Ostapyk, K.; Staveley, J.P.; Verslycke, T.; et al. Pharmaceuticals and Personal Care Products in the Environment: What Are the Big Questions? Environ. Health Perspect. 2012, 120, 1221-1229.

7. Monteiro, S.C.; Boxall, A.B.A. Occurrence and fate of human pharmceuticals in the environment. In Reviews of Environmental Contamination and Toxicology; Whitacre, D.M., Ed.; Springer: Summerfield, NC, USA, 2010; pp. 53-154.

8. Karnjanapiboonwong, A.; Suski, J.G.; Shah, A.A.; Cai, Q.S.; Morse, A.N.; Anderson, T.A. Occurrence of PPCPs at a Wastewater Treatment Plant and in Soil and Groundwater at a Land Application Site. Water Air Soil Pollut. 2011, 216, 257-273.

9. Loganathan, B.; Phillips, M.; Mowery, H.; Jones-Lepp, T.L. Contamination profiles and mass loadings of macrolide antibiotics and illicit drugs from a small urban wastewater treatment plant. Chemosphere 2009, 75, 70-77.

10. Wilson, B.; Chen, R.F.; Cantwell, M.; Gontz, A.; Zhu, J.; Olsen, C.R. The partitioning of triclosan between aqueous and particulate bound phases in the Hudson River Estuary. Mar. Pollut. Bull. 2009, 59, 207-212.

11. Katz, B.G.; Griffin, D.W.; Davis, J.H. Groundwater quality impacts from the land application of treated municipal wastewater in a large karstic spring basin: Chemical and microbiological indicators. Sci. Total Environ. 2009, 407, 2872-2886.

12. Yu, C.P.; Chu, K.H. Occurrence of pharmaceuticals and personal care products along the West Prong Little Pigeon River in east Tennessee, USA. Chemosphere 2009, 75, 1281-1286.

13. Guo, Y.C.; Krasner, S.W. Occurrence of primidone, carbamazepine, caffeine, and precursors for n-nitrosodimethylamine in drinking water sources impacted by wastewater. J. Am. Water Resour. Assoc. 2009, 45, 58-67.

14. Benotti, M.J.; Trenholm, R.A.; Vanderford, B.J.; Holady, J.C.; Stanford, B.D.; Snyder, S.A. Pharmaceuticals and endocrine disrupting compounds in US drinking water. Environ. Sci. Technol. 2009, 43, 597-603.

15. Daughton, C.G.; Ruhoy, I.S. The afterlife of drugs and the role of PharmEcovigilance. Drug Saf. 2008, 31, 1069-1082. 
16. Daughton, C.G. Pharmaceutical ingredients in drinking water: Overview of occurrence and significance of human health considerations. In Contaminants of Emerging Concern in the Environment: Ecological and Human Health Considerations; Rolf, U.H., Ed.; American Chemical Society: Washington, DC, USA, 2010; pp. 9-68.

17. Snyder, A.S. Occurrence of pharmaceuticals in U.S. drinking water. In Contaminants of Emerging Concern in the Environment: Ecological and Human Health Considerations; Rolf, U.H., Ed.; American Chemical Society: Washington, DC, USA, 2010; pp. 69-80.

18. Aydin, E.; Talinli, I. Analysis, occurrence and fate of commonly used pharmaceuticals and hormones in the Buyukcekmece Watershed, Turkey. Chemosphere 2013, 90, 2004-2012.

19. Brodin, T.; Fick, J.; Jonsson, M.; Klaminder, J. Dilute concentrations of a psychiatric drug alter behavior of fish from natural populations. Science 2013, 339, 814-815.

20. Fair, P.A.; Lee, H.B.; Adams, J.; Darling, C.; Pacepavicius, G.; Alaee, M.; Bossart, G.D.; Henry, N.; Muir, D. Occurrence of triclosan in plasma of wild Atlantic bottlenose dolphins (Tursiops truncatus) and in their environment. Environ. Pollut. 2009, 157, 2248-2254.

21. Owen, S.F.; Huggett, D.B.; Hutchinson, T.H.; Hetheridge, M.J.; Kinter, L.B.; Ericson, J.F.; Sumpter, J.P. Uptake of propranolol, a cardiovascular pharmaceutical, from water into fish plasma and its effects on growth and organ biometry. Aquati. Toxicol. 2009, 93, 217-224.

22. Christenson, T. Fish on morphine: Protecting Wisconsin's natural resources through a comprehensive plan for proper disposal of pharmaceuticals. Wiscon. Law Rev. 2008, 141-179.

23. Kwon, J.W.; Armbrust, K.L. Laboratory persistence and fate of fluoxetine in aquatic environments. Environ. Toxicol. Chem. 2006, 25, 2561-2568.

24. Mearns, A.J.; Reish, D.J.; Oshida, P.S.; Buchman, M.; Ginn, T.; Donnelly, R. Effects of pollution on marine organisms. Water Environ. Res. 2009, 81, 2070-2125.

25. Brozinski, J.-M.; Lahti, M.; Meierjohann, A.; Oikari, A.; Kronberg, L. The anti-inflammatory drugs diclofenac, naproxen and ibuprofen are found in the bile of wild fish caught downstream of a wastewater treatment plant. Environ. Sci. Technol. 2013, 47, 342-348.

26. Cecchini, M.; LoPresti, V. Drug residues store in the body following cessation of use: Impacts on neuroendocrine balance and behavior-Use of the Hubbard sauna regimen to remove toxins and restore health. Med. Hypotheses 2007, 68, 868-879.

27. Rudel, R.A.; Attfield, K.R.; Schifano, J.N.; Brody, J.G. Chemicals causing mammary gland tumors in animals signal new directions for epidemiology, chemicals testing, and risk assessment for breast cancer prevention. Cancer 2007, 109, 2635-2666.

28. Cunningham, V.L.; Binks, S.P.; Olson, M.J. Human health risk assessment from the presence of human pharmaceuticals in the aquatic environment. Regul. Toxicol. Pharmacolog. 2009, 53, 39-45.

29. Fent, K.; Weston, A.A.; Caminada, D. Ecotoxicology of human pharmaceuticals. Aquat. Toxicol. 2006, 76, 122-159.

30. Richardson, M.L.; Bowron, J.M. The fate of pharmaceutical chemicals in the aquatic environment. J. Pharm. Pharmacolog. 1985, 37, 1-12.

31. Daughton, C.G.; Brooks, B.W. Active pharmaceutical ingredients and aquatic organisms. In Environmental Contaminants in Biota: Interpreting Tissue Concentrations, 2nd ed.; Meador, W.B.J., Ed.; Taylor and Francis: Boca Raton, FL, USA, 2011; pp. 281-340. 
32. Le-Minh, N.; Khan, S.J.; Drewes, J.E.; Stuetz, R.M. Fate of antibiotics during municipal water recycling treatment processes. Water Res. 2010, 44, 4295-4323.

33. Ternes, T.A.; Joss, A.; Siegrist, H. Scrutinizing pharmaceuticals and personal care products in wastewater treatment. Environ. Sci. Technol. 2004, 38, 392A-399A.

34. Petrovic, M.; de Alda, M.J.L.; Diaz-Cruz, S.; Postigo, C.; Radjenovic, J.; Gros, M.; Barcelo, D. Fate and removal of pharmaceuticals and illicit drugs in conventional and membrane bioreactor wastewater treatment plants and by riverbank filtration. Philos. Trans. R. Soc. A 2009, 367, 3979-4003.

35. Jones, O.A.H.; Voulvoulis, N.; Lester, J.N. Human pharmaceuticals in wastewater treatment processes. Crit. Rev. Environ. Sci. Technol. 2005, 35, 401-427.

36. Onesios, K.M.; Yu, J.T.; Bouwer, E.J. Biodegradation and removal of pharmaceuticals and personal care products in treatment systems: A review. Biodegradation 2009, 20, 441-466.

37. Snyder, S.A. Occurrence, treatment, and toxicological relevance of EDCs and pharmaceuticals in water. Ozone Sci. Eng. 2008, 30, 65-69.

38. Ikehata, K.; Naghashkar, N.J.; Ei-Din, M.G. Degradation of aqueous pharmaceuticals by ozonation and advanced oxidation processes: A review. Ozone Sci. Eng. 2006, 28, 353-414.

39. Yargeau, V.; Leclair, C. Impact of operating conditions on decomposition of antibiotics during ozonation: A review. Ozone Sci. Eng. 2008, 30, 175-188.

40. Werner, J.J.; McNeill, K.; Arnold, W.A. Photolysis of chlortetracycline on a clay surface. $J$. Agric. Food Chem. 2009, 57, 6932-6937.

41. Santoke, H.; Song, W.H.; Cooper, W.J.; Greaves, J.; Miller, G.E. Free-radical-induced oxidative and reductive degradation of fluoroquinolone pharmaceuticals: kinetic studies and degradation mechanism. J. Phys. Chem. A 2009, 113, 7846-7851.

42. Hu, L.; Martin, H.M.; Arcs-Bulted, O.; Sugihara, M.N.; Keatlng, K.A.; Strathmann, T.J. Oxidation of carbamazepine by $\mathrm{Mn}(\mathrm{VII})$ and $\mathrm{Fe}(\mathrm{VI})$ : Reaction kinetics and mechanism. Environ. Sci. Technol. 2009, 43, 509-515.

43. Leech, D.M.; Snyder, M.T.; Wetzel, R.G. Natural organic matter and sunlight accelerate the degradation of 17 beta-estradiol in water. Sci. Total Environ. 2009, 407, 2087-2092.

44. Benotti, M.J.; Brownawell, B.J. Microbial degradation of pharmaceuticals in estuarine and coastal seawater. Environ. Pollut. 2009, 157, 994-1002.

45. Yu, T.H.; Lin, A.Y.C.; Lateef, S.K.; Lin, C.F.; Yang, P.Y. Removal of antibiotics and non-steroidal anti-inflammatory drugs by extended sludge age biological process. Chemosphere 2009, 77, 175-181.

46. Wu, C.X.; Spongberg, A.L.; Witter, J.D. Sorption and biodegradation of selected antibiotics in biosolids. J. Environ. Sci. Health Tox. Hazard. Subst. Environ. Eng. 2009, 44, 454-461.

47. Wu, C.X.; Spongberg, A.L.; Witter, J.D. Adsorption and degradation of triclosan and triclocarban in solis and biosolids-amended soils. J. Agric. Food Chem. 2009, 57, 4900-4905.

48. Chang, P.H.; Li, Z.H.; Yu, T.L.; Munkhbayer, S.; Kuo, T.H.; Hung, Y.C.; Jean, J.S.; Lin, K.H. Sorptive removal of tetracycline from water by palygorskite. J. Hazard. Mater. 2009, 165, $148-155$. 
49. Wilcox, J.D.; Bahr, J.M.; Hedman, C.J.; Hemming, J.D.C.; Barman, M.A.E.; Bradbury, K.R. Removal of organic wastewater contaminants in septic systems using advanced treatment technologies. J. Environ. Qual. 2009, 38, 149-156.

50. Phillips, P.J.; Smith, S.G.; Kolpin, D.W.; Zaugg, S.D.; Buxton, H.T.; Furlong, E.T.; Esposito, K.; Stinson, B. Pharmaceutical formulation facilities as sources of opioids and other pharmaceuticals to wastewater treatment plant effluents. Environ. Sci. Technol. 2010, 44, 4910-4916.

51. Nagarnaik, P.M.; Batt, A.L.; Boulanger, B. Healthcare facility effluents as point sources of select pharmaceuticals to municipal wastewater. Water Environ. Res. 2012, 84, 339-345.

52. Daughton, C.G.; Ruhoy, I.S. Environmental footprint of pharmaceuticals: The significance of factors beyond direct excretion to sewers. Environ. Toxicol. Chem. 2009, 28, 2495-2521.

53. Ruhoy, I.S.; Daughton, C.G. Types and quantities of leftover drugs entering the environment via disposal to sewage—-Revealed by coroner records. Sci. Total Environ. 2007, 388, 137-148.

54. Glassmeyer, S.T.; Hinchey, E.K.; Boehme, S.E.; Daughton, C.G.; Ruhoy, I.S.; Conerly, O.; Daniels, R.L.; Lauer, L.; McCarthy, M.; Nettesheim, T.G.; et al. Disposal practices for unwanted residential medications in the United States. Environ. Int. 2009, 35, 566-572.

55. Seehusen, D.A.; Edwards, J. Patient practices and beliefs concerning disposal of medications. J. Am. Board Fam. Med. 2006, 19, 542-547.

56. Kotchen, M.; Kallaos, J.; Wheeler, K.; Wong, C.; Zahller, M. Pharmaceuticals in wastewater: Behavior, preferences, and willingness to pay for a disposal program. J. Environ. Manag. 2009, 90, 1476-1482.

57. USEPA. Summary of the Clean Water Act. Available online: http://www2.epa.gov/laws-regulations/ summary-clean-water-act (accessed on 1 August 2013).

58. Heidler, J.; Halden, R.U. Meta-analysis of mass balances examining chemical fate during wastewater treatment. Environ. Sci. Technol. 2008, 42, 6324-6332.

59. McClellan, K.; Halden, R.U. Pharmaceuticals and personal care products in archived US biosolids from the 2001 EPA national sewage sludge survey. Water Res. 2010, 44, 658-668.

60. Fick, J.; Soderstrom, H.; Lindberg, R.H.; Phan, C.; Tysklind, M.; Larsson, D.G.J. Contamination of surface, ground, and drinking water from pharmaceutical production. Environ. Toxicol. Chem. 2009, 28, 2522-2527.

61. Larsson, D.G.J.; de Pedro, C.; Paxeus, N. Effluent from drug manufactures contains extremely high levels of pharmaceuticals. J. Hazard. Mater. 2007, 148, 751-755.

62. Edwards, M.; Topp, E.; Metcalfe, C.D.; Li, H.; Gottschall, N.; Bolton, P.; Curnoe, W.; Payne, M.; Beck, A.; Kleywegt, S.; et al. Pharmaceutical and personal care products in tile drainage following surface spreading and injection of dewatered municipal biosolids to an agricultural field. Sci. Total Environ. 2009, 407, 4220-4230.

63. Lapen, D.R.; Topp, E.; Metcalfe, C.D.; Li, H.; Edwards, M.; Gottschall, N.; Bolton, P.; Curnoe, W.; Payne, M.; Beck, A. Pharmaceutical and personal care products in tile drainage following land application of municipal biosolids. Sci. Total Environ. 2008, 399, 50-65.

64. Lin, A.Y.C.; Yu, T.H.; Lin, C.F. Pharmaceutical contamination in residential, industrial, and agricultural waste streams: Risk to aqueous environments in Taiwan. Chemosphere 2008, 74, $131-141$. 
65. Phillips, P.; Chalmers, A. Wastewater effluent, combined sewer overflows, and other sources of organic compounds to Lake Champlain. J. Am. Water Resour. Assoc. 2009, 45, 45-57.

66. Shala, L.; Foster, G.D. Surface water concentrations and loading budgets of pharmaceuticals and other domestic-use chemicals in an urban watershed (Washington, DC, USA). Arch. Environ. Contam. Toxicol. 2010, 58, 551-561.

67. Halden, R.U.; Paull, D.H. Co-occurrence of triclocarban and triclosan in US water resources. Environ. Sci. Technol. 2005, 39, 1420-1426.

68. Fram, M.S.; Belitz, K. Occurrence and concentrations of pharmaceutical compounds in groundwater used for public drinking-water supply in California. Sci. Total Environ. 2011, 409, 3409-3417.

69. Deo, R.P.; Halden, R.U. Effect of sample filtration on the quality of monitoring data reported for organic compounds during wastewater treatment. J. Environ. Monit. 2010, 12, 478-483.

70. Sunkara, M.; Wells, M.J.M. Phase II pharmaceutical metabolites acetaminophen glucuronide and acetaminophen sulfate in wastewater. Environ. Chem. 2009, 7, 111-122.

71. Jones, O.A.; Lester, J.N.; Voulvoulis, N. Pharmaceuticals: A threat to drinking water? Trends Biotechnol. 2005, 23, 163-167.

72. Yu, Y.; Wu, L.; Chang, A.C. Seasonal variation of endocrine disrupting compounds, pharmaceuticals and personal care products in wastewater treatment plants. Sci. Total Environ. 2013, 442, 310-316.

73. Wilde, M.L.; Kummerer, K.; Martins, A.F. Multivariate optimization of analytical methodology and a first attempt to an environmental risk assessment of beta-blockers in hospital wastewater. $J$. Braz. Chem. Soc. 2012, 23, 1732-1740.

74. Ferrari, B.; Paxeus, N.; Lo Giudice, R.; Pollio, A.; Garric, J. Ecotoxicological impact of pharmaceuticals found in treated wastewaters: Study of carbamazepine, clofibric acid, and diclofenac. Ecotoxicol. Environ. Saf. 2003, 55, 359-370.

75. Vazquez-Roig, P.; Andreu, V.; Onghena, M.; Blasco, C.; Pico, Y. Assessment of the occurrence and distribution of pharmaceuticals in a Mediterranean wetland (L'Albufera, Valencia, Spain) by LC-MS/MS. Anal. Bioanal. Chem. 2011, 400, 1287-1301.

76. Carlsson, C.; Johansson, A.K.; Alvan, G.; Bergman, K.; Kuhler, T. Are pharmaceuticals potent environmental pollutants? Part II: Environmental risk assessments of selected pharmaceutical excipients. Sci. Total Environ. 2006, 364, 88-95.

77. Agerstrand, M.; Ruden, C. Evaluation of the accuracy and consistency of the Swedish environmental classification and information system for pharmaceuticals. Sci. Total Environ. 2010, 408, 2327-2339.

78. Zheng, Q.; Zhang, R.J.; Wang, Y.H.; Pan, X.H.; Tang, J.H.; Zhang, G. Occurrence and distribution of antibiotics in the Beibu Gulf, China: Impacts of river discharge and aquaculture activities. Mar. Environ. Res. 2012, 78, 26-33.

79. Miller, K.J.; Meek, J. Helena Valley Ground Water: Pharmaceuticals, Personal Care Products, Endocrine Disruptors (PPCPS) and Microbial Indicators of Faecal Contamination; Montana Department of Environmental Quality: Helena, MT, USA, 2006. 
80. Barnes, K.K.; Kolpin, D.W.; Furlong, E.T.; Zaugg, S.D.; Meyer, M.T.; Barber, L.B. A national reconnaissance of pharmaceuticals and other organic wastewater contaminants in the United States-I) Groundwater. Sci. Total Environ. 2008, 402, 192-200.

81. Bartelt-Hunt, S.; Snow, D.D.; Damon-Powell, T.; Miesbach, D. Occurrence of steroid hormones and antibiotics in shallow groundwater impacted by livestock waste control facilities. J. Contam. Hydrol. 2011, 123, 94-103.

82. Fang, Y.; Karnjanapiboonwong, A.; Chase, D.A.; Wang, J.F.; Morse, A.N.; Anderson, T.A. Occurrence, fate, and persistence of gemfibrozil in water and soil. Environ. Toxicol. Chem. 2012, $31,550-555$.

83. Watanabe, N.; Bergamaschi, B.A.; Loftin, K.A.; Meyer, M.T.; Harter, T. Use and environmental occurrence of antibiotics in freestall dairy farms with manured forage fields. Environ. Sci. Technol. 2010, 44, 6591-6600.

84. Mackie, R.I.; Koike, S.; Krapac, I.; Chee-Sanford, J.; Maxwell, S.; Aminov, R.I. Tetracycline residues and tetracycline resistance genes in groundwater impacted by swine production facilities. Anim. Biotechnol. 2006, 17, 157-176.

85. Zhao, S.; Zhang, P.F.; Crusius, J.; Kroeger, K.D.; Bratton, J.F. Use of pharmaceuticals and pesticides to constrain nutrient sources in coastal groundwater of northwestern Long Island, New York, USA. J. Environ. Monit. 2011, 13, 1337-1343.

86. Wang, C.A.; Shi, H.L.; Adams, C.D.; Gamagedara, S.; Stayton, I.; Timmons, T.; Ma, Y.F. Investigation of pharmaceuticals in Missouri natural and drinking water using high performance liquid chromatography-tandem mass spectrometry. Water Res. 2011, 45, 1818-1828.

87. Stackelberg, P.E.; Furlong, E.T.; Meyer, M.T.; Zaugg, S.D.; Henderson, A.K.; Reissman, D.B. Persistence of pharmaceutical compounds and other organic wastewater contaminants in a conventional drinking-watertreatment plant. Sci. Total Environ. 2004, 329, 99-113.

88. Stackelberg, P.E.; Gibs, J.; Furlong, E.T.; Meyer, M.T.; Zaugg, S.D.; Lippincott, R.L. Efficiency of conventional drinking-water-treatment processes in removal of pharmaceuticals and other organic compounds. Sci. Total Environ. 2007, 377, 255-272.

89. Snyder, S.A.; Adham, S.; Redding, A.M.; Cannon, F.S.; DeCarolis, J.; Oppenheimer, J.; Wert, E.C.; Yoon, Y. Role of membranes and activated carbon in the removal of endocrine disruptors and pharmaceuticals. Desalination 2007, 202, 156-181.

90. Kim, S.D.; Cho, J.; Kim, I.S.; Vanderford, B.J.; Snyder, S.A. Occurrence and removal of pharmaceuticals and endocrine disruptors in South Korean surface, drinking, and waste waters. Water Res. 2007, 41, 1013-1021.

91. Loraine, G.A.; Pettigrove, M.E. Seasonal variations in concentrations of pharmaceuticals and personal care products in drinking water and reclaimed wastewater in Southern California. Environ. Sci. Technol. 2006, 40, 687-695.

92. Trenholm, R.A.; Vanderford, B.J.; Snyder, S.A. On-line solid phase extraction LC-MS/MS analysis of pharmaceutical indicators in water: A green alternative to conventional methods. Talanta 2009, 79, 1425-1432.

93. PBT Profiler software. Available online: http://www.pbtprofiler.net (accessed on 1 August 2013). 
94. Hernando, M.D.; Mezcua, M.; Fernandez-Alba, A.R.; Barcelo, D. Environmental risk assessment of pharmaceutical residues in wastewater effluents, surface waters and sediments. Talanta 2006, 69, 334-342.

95. Carlsson, C.; Johansson, A.K.; Alvan, G.; Bergman, K.; Kuhler, T. Are pharmaceuticals potent environmental pollutants? Part I: Environmental risk assessments of selected active pharmaceutical ingredients. Sci. Total Environ. 2006, 364, 67-87.

96. Hernando, M.D.; Gomez, M.J.; Aguera, A.; Fernandez-Alba, A.R. LC-MS analysis of basic pharmaceuticals (beta-blockers and anti-ulcer agents) in wastewater and surface water. Trac Trends Anal. Chem. 2007, 26, 581-594.

97. Clarke, B.O.; Smith, S.R. Review of 'emerging' organic contaminants in biosolids and assessment of international research priorities for the agricultural use of biosolids. Environ. Int. 2011, 37, 226-247.

98. Clarke, B.O.; Porter, N.A. Persistent organic pollutants in sewage sludge: Levels, sources, and trends. In Contaminants of Emerging Concern in the Environment: Ecological and Human Health Considerations; Rolf, U.H., Ed.; American Chemical Society: Washington, DC, USA, 2010; pp. 137-171.

99. Harrison, E.Z.; Oakes, S.R.; Hysell, M.; Hay, A. Organic chemicals in sewage sludges. Sci. Total Environ. 2006, 367, 481-497.

100. Rogers, H.R. Sources, behaviour and fate of organic contaminants during sewage treatment and in sewage sludges. Sci. Total Environ. 1996, 185, 3-26.

101. New England Bicycle Racing Association. A National Biosolids Regulation, Quality, End Use \& Disposal Survey; Final Report; New England Bicycle Racing Association: Tamworth, NH, UK, 2007.

102. Xu, J.; Chen, W.P.; Wu, L.S.; Green, R.; Chang, A.C. Leachability of some emerging contaminants in reclaimed municipal wastewater-irrigated turf grass fields. Environ. Toxicol. Chem. 2009, 28, 1842-1850.

103. Xia, K.; Hundal, L.S.; Kumar, K.; Armbrust, K.; Cox, A.E.; Granato, T.C. Triclocarban, triclosan, polybrominated diphenyl ethers, and 4-nonylphenol in biosolids and in soil receiving 33-year biosolids application. Environ. Toxicol. Chem. 2010, 29, 597-605.

104. Smith, S.R. Organic contaminants in sewage sludge (biosolids) and their significance for agricultural recycling. Philos. Trans. R. Soc. A 2009, 367, 4005-4041.

105. Wu, C.X.; Spongberg, A.L.; Witter, J.D.; Fang, M.; Ames, A.; Czajkowski, K.P. Detection of Pharmaceuticals and Personal Care Products in Agricultural Soils Receiving Biosolids Application. Clean Soil Air Water 2010, 38, 230-237.

106. Dolliver, H.; Kumar, K.; Gupta, S. Sulfamethazine uptake by plants from manure-amended soil. J. Environ. Qual. 2007, 36, 1224-1230.

107. Kumar, K.; Gupta, S.C.; Baidoo, S.K.; Chander, Y.; Rosen, C.J. Antibiotic uptake by plants from soil fertilized with animal manure. J. Environ. Qual. 2005, 34, 2082-2085.

108. Holling, C.S.; Bailey, J.L.; Heuvel, B.V.; Kinney, C.A. Uptake of human pharmaceuticals and personal care products by cabbage (Brassica campestris) from fortified and biosolids-amended soils. J. Environ. Monit. 2012, 14, 3029-3036. 
109. Klavarioti, M.; Mantzavinos, D.; Kassinos, D. Removal of residual pharmaceuticals from aqueous systems by advanced oxidation processes. Environ. Int. 2009, 35, 402-417.

110. Sharma, V.K. Oxidative transformations of environmental pharmaceuticals by $\mathrm{Cl}-2, \mathrm{ClO} 2, \mathrm{O}-3$, and $\mathrm{Fe}(\mathrm{VI})$ : Kinetics assessment. Chemosphere 2008, 73, 1379-1386.

111. Ikehata, K.; Gamal El-Din, M.; Snyder, S.A. Ozonation and advanced oxidation treatment of emerging organic pollutants in water and wastewater. Ozone Sci. Eng. J. Int. Ozone Assoc. 2008, 30, 21-26.

112. Esplugas, S.; Bila, D.M.; Krause, L.G.T.; Dezotti, M. Ozonation and advanced oxidation technologies to remove endocrine disrupting chemicals (EDCs) and pharmaceuticals and personal care products (PPCPs) in water effluents. J. Hazard. Mater. 2007, 149, 631-642.

113. Ellis, W.C.; Tran, C.T.; Roy, R.; Rusten, M.; Fischer, A.; Ryabov, A.D.; Blumberg, B.; Collins, T.J. Designing green oxidation catalysts for purifying environmental waters. J. Am. Chem. Soc. 2010, 132, 9774-9781.

114. Daughton, C.G. Cradle-to-cradle stewardship of drugs for minimizing their environmental disposition while promoting human health. II. Drug disposal, waste reduction, and future directions. Environ. Health Perspect. 2003, 111, 775-785.

115. Kummerer, J.; Hempel, M. Green and Sustainable Pharmacy, 1st ed.; Springer-Verlag: Berlin Heidelberg, Germany, 2010.

(C) 2013 by the authors; licensee MDPI, Basel, Switzerland. This article is an open access article distributed under the terms and conditions of the Creative Commons Attribution license (http://creativecommons.org/licenses/by/3.0/). 